\title{
Workload Control in Additive Manufacturing Shops where Post-Processing is a Constraint: An Assessment by Simulation
}

Matthias Thürer* (corresponding author: matthiasthurer@workloadcontrol.com), Yuan Huang, and Mark Stevenson

\author{
Name: $\quad$ Prof. Matthias Thürer \\ Institution: Jinan University \\ Address: $\quad$ School of Intelligent Systems Science and Engineering \\ Jinan University (Zhuhai Campus) \\ 519070, Zhuhai, PR China \\ E-mail: matthiasthurer@workloadcontrol.com \\ Name: $\quad$ Dr. Yuan Huang \\ Institution: Cardiff University \\ Address: $\quad$ Logistics and Operations Management Section \\ Cardiff Business School \\ Cardiff University \\ CF10 3EU - U.K \\ E-mail: $\quad$ huangy66@cardiff.ac.uk \\ Name: $\quad$ Prof. Mark Stevenson \\ Institution: Lancaster University \\ Address: Department of Management Science \\ Lancaster University Management School \\ Lancaster University \\ LA1 4YX - U.K. \\ E-mail: $\quad$ m.stevenson@lancaster.ac.uk
}

Keywords: Workload Control; Order Release; Dispatching; Advanced Manufacturing Processes; $3 D$ Printing. 


\title{
Workload Control in Additive Manufacturing Shops where Post-Processing is a Constraint: An Assessment by Simulation
}

\begin{abstract}
Additive Manufacturing (AM) shops typically produce high variety, low volume products on a to-order basis. Products are first created in parallel batches at a single AM station before being subjected to several post-processing operations. While there exists an emerging literature on AM station scheduling and order book smoothing, this literature has largely neglected downstream post-processing operations, which also affect overall performance. Workload Control provides a unique production control solution for these post-processing operations, but the specific AM shop structure has been neglected in the literature. Using simulation, this study shows that load balancing via the use of workload norms, as is typical for Workload Control, becomes ineffective since the norm must allow for the operation throughput time at the AM station and for its variability. A sequencing rule for the jobs waiting to be released that inherently creates a mix of jobs that balances the workload is therefore identified as the bestperforming rule. These findings reinforce the principle that load limiting should be used at upstream stations whereas sequencing should be applied at downstream stations. Finally, although the focus is on AM shops, the findings have implications for other shops with similar structures, e.g. in the steel and semi-conductor industries.
\end{abstract}

Keywords: Workload Control; Order Release; Dispatching; Advanced Manufacturing Processes; 3D Printing. 


\section{Introduction}

Additive Manufacturing (AM) - typically in the form of 3D printing (Berman, 2012) - has received growing interest in recent years from scholars in management fields due to its increasing application for creating commercial products (Khorram Niaki \& Nonino, 2016). Despite AM representing a revolutionary manufacturing solution with the potential to extend the performance frontiers of operations and supply chains (Brennan et al., 2015; Holmström et al., 2016; McCarthy et al., 2016; Eyers et al., 2018; Hedenstierna et al., 2019), organizations have been facing implementation challenges, particularly how to integrate the AM operation with the other (pre-existing) processes in order to realize the anticipated performance improvements (Mellor et al., 2014; Thomas-Seale et al., 2018; Delic et al., 2019). For example, Delic et al. (2019) highlighted that traditional supply chain activities will continue to exist alongside $\mathrm{AM}$ and stressed the importance of understanding the interaction effects between AM and traditional operations. Indeed, the performance of AM is largely dependent on the embedding of AM into a supportive production system (Mellor et al., 2014) and the coherence between various functions, such as design, the AM process and settings, and post-AM operations, within the production system (Thomas-Seale et al., 2018). In this AM context, our study assesses the potential of rule-based Workload Control order release (Haeussler \& Netzer, 2019) to control post-processing operations.

The study was triggered by a visit to a 3D printing shop by one of the authors as part of a broader research initiative on 3D printing in March 2019. Like many other new players in the 3D printing industry, 'Company $\mathrm{X}$ ' started its 3D printing business with a simple setting - a printing operation followed by post-processes. The design of items and their digitalization to appropriate 3D printing manufacturing specifications (i.e. pre-processes) are executed by the customers. Typical products include consumer models (e.g. of trains and figures) and prototyping parts. Products vary to a great extent in terms of their shape, size, colour, and quality specification (e.g. thickness of printing layers), and the items to be printed to complete each order are only known upon the arrival of the order. As is typical for this type of shop (Mellor et al., 2014; Ryan et al., 2017; Eyers et al., 2018), Company X operates as an engineerto-order shop producing high variety, low volume products.

The 3D printing technology used in Company $\mathrm{X}$ is a Polyjet printer, where the print-head jets materials (e.g. crystal) onto a flat platform layer by layer to create 3D printed products. All products visit this AM station that is able to handle different types of products within a single batch. This is then followed by a set of post-processing stations, depending on the specific needs of individual products. In general, post-processing consists of removing support 
structures and finishing the surface (Alexander et al., 1998). During the company visit, the researcher observed six stations: the freezer, oven, oil bath, salt bath, dehydrator, and keyway check. In addition, there is an inspection process for a sample of products and, in general, there is also packaging.

While there are some new scheduling challenges introduced by the AM operation and some emerging solutions (Li et al., 2017; Chergui et al., 2018), delivery time performance appears to be largely determined by the post-processing operations, which may significantly constrain the AM system (Mellor et al., 2014; Thomas-Seale et al., 2018). More specifically, and as observed in our initial case that triggered this study, products manufactured at the AM station require different post-processing stations (and in different sequences). This results in a general flow shop (Enns, 1995) downstream of the AM station with stochastic routings and processing times, where jobs have to compete for resources. This in turn causes difficulties for production planning and control and, as a result, problems in adhering to promised due dates.

Workload Control is a production control concept developed for complex high-variety environments such as the general flow shop (Zäpfel \& Missbauer, 1993; Stevenson et al., 2005). A main production control function of Workload Control is order release control. When order release control is applied, jobs do not enter the shop floor directly. Instead, they are retained in a pre-shop pool or order book (Hedenstierna et al., 2019) and released using criteria that allow the shop to achieve certain performance targets, e.g. to restrict the level of work-inprocess inventory and/or maximize due date adherence. Given its importance, a broad literature has emerged that assessed the performance of Workload Control order release both through simulation (e.g. Land \& Gaalman, 1998; Perona \& Portioli, 1998; Sabuncuoglu \& Karapinar, 2000; Cigolini, \& Portioli-Staudacher, 2002; Portioli-Staudacher \& Tantardini, 2012; Fernandes et al., 2011; Thürer et al., 2012, 2014; Fernandes et al., 2016; Gonzalez-R et al., 2018) and in practice (e.g. Wiendahl, 1992; Bechte 1994; Hendry et al., 2013; Silva et al., 2015; Hutter et al., 2018). These studies highlight the potential of Workload Control in complex high-variety shops meaning it has the potential to provide a solution to the planning and control needs of AM shops.

Although order book smoothing has been recognized as a distinct means of managing demand variability in AM shops (Hedenstierna et al., 2019), the AM literature mainly focusses on the control of the AM station. Meanwhile, the AM shop also poses new challenges not previously considered in the Workload Control literature. In an "AM shop", all jobs must first visit the AM station before entering the general flow shop. To the best of our knowledge, only two prior Workload Control study considered a similar shop structure. First, Fernandes et al. 
(2015) assessed the impact of allowing for semi-finished products in a make-to-order shop where a single machine extruding aluminum profiles precedes a job shop. The authors showed that exercising order release control only at downstream stations leads to similar performance when compared to exercising release control at the single extrusion station that is the first in the routing of all jobs and at the downstream stations. But this runs counter to the argument put forward in the second study, by Cransberg et al. (2016) who presented a single case of a company where several different batch processes follow each other, which is similar to the serial-batching scheduling problem (Pei et al., 2019a) discussed in the wider scheduling literature for deterministic demand, including in the context of steel making (Pei et al. 2019b; Kong et al., 2020). Cransberg et al. (2016) argued that if the complexity to be controlled resides at an upstream station then it should be controlled at order release while if the complexity to be controlled resides at a downstream station then it should be controlled by dispatching.

The above highlights that Workload Control order release is of particular relevance to shops that provide AM services, but its performance impact remains unclear. Moreover, it remains unknown whether any adaptations to the original Workload Control concept are required to enhance its applicability to this context. In response, this study assesses the performance of Workload Control in a general flow shop with a single station that is the first in the routing of all jobs. During the experiments we consider different solutions that characterize the design of Workload Control: when a release decision is taken and in which sequence orders are considered for release. This provides important information on whether and how Workload Control order release needs to be adapted for AM shops. While our focus is on AM shops, the findings are also of significance to other contexts such as the manufacturing contexts considered in Fernandes et al. (2015) and Cransberg et al. (2016), the steel industry (Pei et al., 2019a), as well as to semi-conductor plants, which also often have an initial batch process that is the first step in the routing of all jobs (see, e.g. Kacar et al., 2012).

\section{Background}

\subsection{Additive Manufacturing}

The distinctive feature of an AM process - joining materials layer upon layer to create products from digital data on 3-Dimensional (3D) models (ASTM, 2012) - offers innovative flexibilities in design and fabrication (Eyers et al., 2018). This makes this automated production technology of specific relevance to high-variety low-volume production and to pull-based supply chains (Tuck et al., 2008; Berman, 2012; Liu et al., 2014; Ryan et al., 2017). Further, the simplified 
tooling/set-up requirements and high-variety batching options in AM fabrication processes have the potential to significantly reduce manufacturing lead times and the costs of customized production (Holmström et al., 2010; Petrovic et al., 2011; Achillas et al., 2015).

Yet, the increasing popularity of AM technologies for commercial use, particularly for manufacturing components and end-use items, also provokes a new range of complex production planning and control issues (Pour et al., 2016; Li et al., 2017; Chergui et al., 2018). For example, given the significant efficiency improvement of a multi-part build compared to a single-part build (Piili et al., 2015), the utilization of the production area (build envelope) becomes an important performance indicator for AM planning solutions in addition to due date and lead time performance (Chergui et al., 2018). Parts can be produced in a high-variety batch in order to reduce AM processing times (Rickenbacher et al., 2013) and/or material wastage. But although there has been increasing interest in AM in the scheduling literature, how to control post-AM processing remains widely neglected.

These post-AM processing operations are an integral part of an AM production system as the AM process itself does not create net shape parts (Mellor et al., 2014; Eyers \& Potter, 2015; Thomas-Seale et al., 2018). The performance of the post-AM processing shop is consequently vital to the successful implementation and integration of AM shops, as has been stressed in recent empirical studies (Mellor et al., 2014; Thomas-Seale et al., 2018). Post-processing operations include support removal, surface finishing, heat treatment, part collation, quality assessment, etc., all of which have distinctly different characteristics. They can be machine and/or non-machine driven, where multiple stations, including traditional machining (e.g. grinding, blasting, photoablation, industrial etching) and manual work, might be involved (Thomas-Seale et al., 2018). This results in some form of general flow shop (Enns, 1995) with stochastic routings and processing times, and where jobs have to compete for resources. Indeed, both human and machine constraints at post-AM processing operations have been reported as barriers to effective AM shops (Mellor et al., 2014; Eyers et al., 2018; Thomas-Seale et al., 2018).

Workload Control, and its order release function, provides an effective control solution for high-variety contexts. It consequently appears to be a highly relevant control solution for the post-processing shop and for the AM shop as a whole. However, the distinctive complexities that arise from integrating the AM station into the shop as the gateway step in the routing sequence of all jobs has not received sufficient attention in the Workload Control literature. As such, this study investigates the application of Workload Control order release to an AM shop. Workload Control order release will be introduced next. 


\subsection{Workload Control Order Release}

Haeussler \& Netzer (2019) subdivided Workload Control into rule-based and optimizationbased Workload Control. This study focusses on rule-based Workload Control, which essentially has no planning function. As such, we execute production control only and there is also no hierarchical structure into which Workload Control is embedded. There are many rulebased order release methods in the Workload Control literature; for examples, see the reviews by Wisner (1995), Land \& Gaalman (1996), Bergamaschi et al. (1997), and Fredendall et al. (2010). In this paper, the following release procedure will be used to keep the workload $W_{s}$ released to a station $s$ within a pre-established workload norm $N_{s}$. First, all jobs in the set of jobs $J$ in the pre-shop pool are sorted following a pool sequencing rule as part of the sequencing decision. Then, the selection decision is executed as follows:

(1) The job $j \in J$ with the highest priority is considered for release first.

(2) Take $R_{j}$ to be the ordered set of operations in the routing of job $j$. If job $j$ 's processing time $p_{i j}$ at the $i^{\text {th }}$ operation in its routing - corrected for station position $i$ - together with the workload $W_{s}$ released to station $s$ (corresponding to operation $i$ ) and yet to be completed fits within the workload norm $N_{s}$ at this station, that is $\frac{p_{i j}}{i}+W_{s} \leq N_{s} \forall i \in R_{j}$, then the job is selected for release. That means it is removed from $J$ and its load contribution is included, i.e. $W_{s}:=W_{s}+\frac{p_{i j}}{i} \forall i \in R_{j}$.

Otherwise, the job remains in the pool and its processing time does not contribute to the station load.

(3) If the set of jobs $J$ in the pool contains any jobs that have not yet been considered for release, then return to Step 1 and consider the job with the next highest priority. Otherwise, the release procedure is complete and the selected jobs are released to the shop floor.

Note that since a released job contributes to $W_{s}$ until its operation at this station is completed, the load contribution to a station is calculated by dividing the processing time of the operation at a station by the station's position in a job's routing (Oosterman et al., 2000).

\subsection{Discussion - Workload Control Order Release in AM Shops}

Most shops providing AM services operate as engineer-to-order shops producing a high-variety of products in low volume. A major factor determining the performance of the AM shop is the post-AM processing steps that follow on after the actual AM has taken place. While there exists an emerging literature on the scheduling of the AM station, post-processing has been widely neglected. Workload Control appears to provide a control solution for the post-processing shop. 
However, AM introduces a series of complexities that are not adequately addressed in the Workload Control literature. Based on the description of AM and of Workload Control order release, as provided in Section 2.1 and Section 2.2 above, the following can be observed.

Workload Control order release decisions can be taken at periodic or continuous time intervals. Continuous hereby means whenever the system state changes, i.e. a new job arrives or an operation is completed at a station. For AM, a third option may occur whereby release is driven by the AM station only, since this is a gateway station. This leads to our first research question related to the design of Workload Control in the context of AM:

RQ1: In the context of AM, where an AM station precedes a general flow shop, when should the order release decision be taken?

Once a release is triggered, the sequence in which jobs are considered for release should be determined. There are two objectives in the Workload Control order release literature: timing (or urgency) and workload balancing (Land, 2006). But given the presence of the AM operation as a gateway station to the general flow shop, the pool sequence may also consider the output rate of the AM station. Short operation throughput times at the AM station not only ensure short shop floor throughput times but also ensure quick replenishment at downstream postprocessing queues thereby avoiding potential starvation. This leads to our second research question:

RQ2: What kind of pool sequencing rule should be applied to consider jobs for release to the AM shop?

Simulation will next be used to address these two questions. The simulation results should then indicate whether and how Workload Control order release should be adapted for application in an AM context.

\section{Simulation Model}

While this study is driven by a practical observation, a generalized model is used as AM shops in practice are likely to differ from one another in terms of the AM operation configuration as well as the scale of post-processes. Our generalized model seeks to capture the aspect that is of most interest to us - that a batch process precedes the actual shop where post-processing takes place. So, we extend a generalized model widely used in the literature for capturing the characteristics of general flow shops in practice and incorporate the characteristics of AM 
shops that are of most interest to us. The structure of the high variety to-order environment considered in this study is depicted in Figure 1, where the routing probability is indicated by the thickness of the arrows. Note that we only focus on the control of the actual manufacturing process, neglecting design, and that the AM station is deliberately not the single operational constraint, given our focus on the control of the post-processing shop.

\section{[Take in Figure 1]}

\subsection{Overview of Modeled Shop and Job Characteristics}

A simulation model of a general flow shop (representing post-AM processing) that is preceded by a single AM station that can process multiple jobs in parallel has been implemented using the SimPy ${ }^{\odot}$ module of Python ${ }^{\odot}$. Our model is stochastic, whereby job routings, processing times, inter-arrival times, and due dates are stochastic (random) variables. While the AM process is represented by a single station, the post-processing shop contains six stations, where each station is a single constant capacity resource.

In the post-processing shop, all stations have an equal probability of being visited and a particular station is required at most once in the routing of a job. The resulting routing length, i.e. the number of operations in the routing of an order, is uniformly distributed between one and six operations and the resulting routing vector (i.e. the sequence in which stations are visited) is sorted to create the random but directed routing that characterizes the general flow shop. The setting of the routing length was chosen in line with previous simulation studies that use similar job shop models (e.g. Land, 2006, Oosterman et al., 2000). It is considered representative of typical AM post-processes, e.g. removing support structures, finishing the surface, heat treatment, inspection, packaging etc. Operation processing times in the postprocessing shop follow a truncated 2-Erlang distribution with a maximum of 4 time units and a mean of 1 time unit after truncation. The 2-Erlang distribution was chosen since it better approaches processing times in real life job shops when compared to an exponential distribution (Oosterman et al., 2000). Set-up times are considered as part of the operation processing time. Meanwhile, the inter-arrival time of orders to the AM shop follows an exponential distribution with a mean of 0.648 , which, based on the number of stations in the routing of an order, deliberately results in a utilization level of $90 \%$ at post-processing stations.

All jobs pass through the AM station before entering the post-processing shop. This AM station is deliberately not the single bottleneck, given our focus on the control of the postprocessing stations. The AM operation is essentially a parallel batch process, i.e. several different parts can be processed in parallel as a single batch. Meanwhile, AM machines have a 
maximum production area (the build envelope) where several jobs can typically be loaded into this production area (Chergui et al., 2018). AM produces jobs layer by layer, i.e. additively. This means that the overall batch processing time is dependent on the speed at which each layer is created and the number of layers required by the largest job in the batch, i.e. its so-called height (Zhang \& Bernard, 2013; Chergui et al., 2018). Consequently, each job in our model has a height and an area. The height follows a 2-Erlang distribution with a mean of 2 space units. To the best of our knowledge there is no information in the literature on the distribution of part heights. The 2-Erlang distribution was chosen to be consistent with the distribution at post-processing. The height is directly related to the processing time, where the production rate is given by 1 space unit per time unit. Note, that the production rate is considered to be independent from the occupied production area to isolate the effect of realized batch processing times and occupancy of the batch area. The area required by each job follows a truncated 2Erlang distribution with a maximum of 10 space units and a mean of 2 space units before truncation. The maximum production (batch) area of the machine (the build envelope) is arbitrarily set to 10 space units.

We cannot predict the utilization of the AM station since this is dependent on the loading of the station and thus the pool sequencing and dispatching rule applied (as will be described below). In fact, the processing time is state dependent (Thürer et al., 2020) in the sense that a longer queue typically means shorter realized processing times per job; and a smaller queue typically means longer realized processing times per job. It is also not clear whether the utilization should consider just the realized batch processing time and the batch size or also include the actual fill rate of the production area. We therefore do not consider that there is a clear measure for the utilization that could be used to set parameters. Parameters for the AM station were therefore set such that the operation throughput times realized at the AM station are similar to the operation throughput times realized at the post-processing stations. Note that we also do not consider different material types, and consequently neglect set-up times at the AM station.

Finally, due dates are set exogenously by adding a random allowance factor, uniformly distributed between 36 and 51 time units, to the job entry time. The allowance factor for the due date was set such that the percentage tardy is about $20 \%$ for an infinite workload norm, i.e. no order release. This target percentage tardy should be neither too high, since rules that reduce the variance of lateness across jobs might even lead to an increase in the percentage tardy when due date allowances are too tight on average, nor too low, to avoid our results being affected 
by incidental effects as very few jobs would be responsible for the performance of the shop (Land et al., 2015). The main shop and job characteristics are summarized in Table 1.

\section{[Take in Table 1]}

\subsection{Workload Control and Refinements}

As in previous simulation studies on Workload Control (e.g. Land \& Gaalman, 1998; Fredendall et al., 2010; Thürer et al., 2012), it is assumed that all jobs are accepted, materials are available, and all necessary information regarding shop floor routings, processing times, etc. is known. Jobs arriving at the AM shop flow into a pre-pool (or order book) to await release according to the release method described in Section 2.2 above. Based on the results in Fernandes et al. (2015), only the post-processing stations are subject to a workload norm. In general, and to the best of our knowledge, it is not possible to derive a meaningful workload measure for rule-based Workload Control for a parallel batch process where the realized workload is given by the maximum workload across jobs in the batch rather than by the aggregate of job workloads.

Eight workload norms - in two time unit intervals from 12 to 26 time units - are considered. The workload norm is a parameter set by management. We use a spectrum for the norm that captures the best performance for all performance measures and experimental settings. As a baseline measure, experiments without controlled order release have also been executed, i.e. where the workload norm is considered to be infinite.

\subsubsection{When Should Release Take Place?}

We consider two continuous release options: (i) Continuous based order release, i.e. release whenever an operation is completed or a new job arrives at the shop, and (ii) AM based, i.e. release whenever a batch is completed at the AM station or a new job arrives at the shop. Note that we do not consider periodic release, which would have to be supplemented by a continuous workload trigger to avoid premature station idleness (Thürer et al., 2012), as this becomes dysfunctional in the modelled context where work from the pool still has to pass the AM station before arriving at the starving station.

\subsubsection{What Pool Sequencing Rule should be Applied?}

Traditionally, Workload Control integrates a timing function and a load balancing function. Both should be reflected in the pool sequencing rule (Thürer et al., 2015). In addition, pool sequencing could also focus on the output rate of the AM station (i.e. the batch size divided by the batch processing time) to reduce shop floor throughput times and to avoid starvation by 
ensuring quick replenishment at the downstream post-processing shop. To reflect these different objectives, nine different pool sequencing rules are considered:

- Planned Release Date (PRD): This is a time-oriented rule that sequences jobs according to planned release dates, as given by Equation (1) below.

$\tau_{j}=\delta_{j}-\sum_{i \in R_{j}} \alpha_{s}$

$\tau_{j}=$ planned release date of job $j$

$\delta_{j}=$ due date of job $j$

$\alpha_{s}=$ allowance for the operation throughput time at station $s$ associated with operation $i$, given by the cumulative moving average, i.e. the average of all operation throughput times realized until the current simulation time

- Capacity Slack CORrected (CSCOR): This is a rule that focusses on workload balancing by sequencing jobs according to a capacity slack ratio based on corrected aggregate load measures, as given by Equation (2) below. This rule integrates three elements into one priority measure: the workload contribution of the job (i.e. the processing time); the load gap at a station; and, the routing length, which is used to average the ratio between the load contribution and load gap elements over all operations in the routing of the job. The lower the capacity slack ratio of job $j\left(S_{j}\right)$, the higher the priority of job $j$. This rule was applied by Thürer et al. (2015). Note that the same rule - but based on an aggregate measure for calculating the load contribution and load gap elements - was originally proposed by Philipoom et al. (1993).

$$
S_{j}=\frac{\sum_{i \in R_{j}}\left(\frac{\frac{p_{i j}}{i}}{N_{S}-W_{S}}\right)}{n_{j}}
$$

$n_{j}=$ routing length (i.e. the number of operations in the routing) of job $j$

- Smallest Area (SA): This rule seeks to increase the number of jobs produced (the batch size) by starting the sequence with the smallest jobs.

- Largest Area ( $L A)$ : This rule seeks to increase space utilization, better filling the production area by starting with large jobs before filling the remaining space with smaller jobs.

- Shortest Height (SH): This rule is equivalent to the shortest processing time rule but based on height. 
- Modified Capacity Slack (MODCS): This rule combines an element based on urgency with an element that expedites jobs when several jobs are tardy. This is similar to the Modified Operation Due Date (MODD) rule, which combines operation due date and shortest processing time dispatching (e.g. Baker \& Kanet, 1983). Two classes of jobs are created for MODCS. One set of urgent jobs for which the planned release date has already passed, and one set of non-urgent jobs consisting of all of the remaining jobs in the pool. Urgent jobs always have priority over non-urgent jobs. Within the class of urgent jobs, jobs are sequenced according to the CSCOR rule. Then, within the class of non-urgent jobs, jobs are sequenced according to the PRD rule. This rule was introduced by Thürer et al. (2015).

- Modified Smallest Area (MODSA): This rule follows the same logic as MODCS, but it focusses on the AM station. Within the class of urgent jobs, jobs are sequenced according to the SA rule. Then, within the class of non-urgent jobs, jobs are sequenced according to the PRD rule.

- Modified Largest Area (MODLA): This rule follows the same logic as MODCS, but it focusses on the AM station. Within the class of urgent jobs, jobs are sequenced according to the LA rule. Then, within the class of non-urgent jobs, jobs are sequenced according to the PRD rule.

- Modified Shortest Height (MODSH): This rule follows the same logic as MODCS, but it focusses on the AM station. Within the class of urgent jobs, jobs are sequenced according to the $\mathrm{SH}$ rule. Then, within the class of non-urgent jobs, jobs are sequenced according to the PRD rule.

\subsection{Shop Floor Dispatching}

Once a job is released, it enters the queue at the AM station. Once it has been processed at the AM station, the job flows directly into the queue of the first post-processing station in its routing. Shop floor dispatching prioritizes jobs waiting to be processed in the queue of a station. There are different objectives for the AM station, which is a batch process, and the postprocessing stations. Consequently, different rules will be applied, as described below.

\subsubsection{What Dispatching Rule should be Applied at the AM Station?}

The AM station is a parallel batch process for which we use a rule-based batching decision. Batching at the AM station was considered at order release as part of the pool sequencing rule. Meanwhile it is realized as part of the rule-based dispatching decision described next. The first decision is the sequence in which jobs should be considered when filling the production area 
at the AM station for processing, which should be aligned with the objectives at pool sequencing. Three different dispatching rules will be applied: PRD, LA and SH. Note that SA is not considered since it resulted in large jobs never being released in preliminary simulation experiments. Note that this is also the reason why we do not include First-Come-First-Served (FCFS) dispatching as a baseline, since the FCFS sequence results in SA dispatching at the AM station under SA pool sequencing. The second is whether or not the production area needs to be full. Both scenarios are considered in this study. If the production area does not need to be full, jobs are processed as soon as there is capacity at the AM station. If the production area needs to be full, jobs are only processed at the AM station if at least one job cannot be loaded. In other words, if one job cannot be loaded, then the batch is considered full. We consider a stochastic context where order arrival and order characteristics follow a stochastic process. As a consequence, there is no visibility of future order arrivals and this is arguably the best criterion to determine whether a batch is full or not.

\subsubsection{Dispatching at the Proceeding Post-AM Processing Stations}

Jobs in the queue at the post-processing stations are prioritized according to operation due dates. The calculation of the operation due date $\delta_{j i}$ for the $i^{\text {th }}$ operation of a job $j$ follows Equation (3). $\delta_{i j}=\delta_{j}-\left(n_{j}-i\right) \cdot a_{s} \quad i: 1 . . n_{j}$

In this study, the allowance for the operation throughput times is given by the cumulative moving average, i.e. the average of all operation throughput times realized until the current simulation time.

\subsection{Experimental Design and Performance Measures}

The experimental factors are summarized in Table 2. A full factorial design was used with 972 $(9 \times 2 \times 9 \times 3 \times 2)$ scenarios, where each scenario was replicated 100 times. All results were collected over 10,000 time units following a warm-up period of 3,000 time units to minimize initialization bias. These parameters allow us to obtain stable results while keeping the simulation run time to a reasonable level. Given that our focus is on to-order shops, the following three main performance measures are considered in this study: lead time - the mean of the completion date minus the pool entry date across jobs; percentage tardy - the percentage of jobs completed after the due date; and, mean tardiness - that is, $T_{j}=\max \left(0, L_{j}\right)$, with $L_{j}$ being the lateness of job $j$ (i.e. the actual delivery date minus the due date of job $j$ ). In addition to the three main performance measures, we also measure the shop floor throughput time as an 
instrumental performance variable. While the lead time includes the time that an order waits before being released, the shop floor throughput time only measures the time after an order is released to the shop floor. Order entry time hereby means the time an order arrives at the AM shop (joining its order pool or book) while order release time refers to the time when the order is released from the pool and enters the queue at the AM station. So, both the lead time and shop floor throughput time include the time the job spends at the AM station, and the interdependencies between the AM station and post-processing shop are reflected in the above time and tardiness related performance measures. Finally, to assess the performance of the AM station we also measure the realized batch processing time, the occupied area and the number of jobs per batch (the batch size). Note that we only focus on operational performance measures and do not consider cost, since costs are firm-specific and cannot be controlled directly. An indication of cost performance in different contexts can be obtained by attaching a contextspecific cost factor to our operational performance measures.

[Take in Table 2]

\section{Results}

To obtain a first indication of the relative impact of the experimental factors, statistical analysis has been conducted by applying an Analysis of Variance (ANOVA). ANOVA is here based on a block design, which is typically used to account for known sources of variation in an experiment. In our ANOVA, we treat the workload norm as the blocking factor. This allows the main effects of this factor and the main and interaction effects of the four factors that are specific to the problem under study - release timing, pool sequencing rule, dispatching AM station, and whether or not the production area needs to be full - to be evaluated. We do not present detailed results due to space limitations. All main and interaction effects, except the four-way interaction in terms of the percentage of tardy jobs, were found to be statistically significant for our three main performance measures. The Scheffé multiple comparison procedure (Scheffé, 1959) was applied to obtain a first indication of the direction and size of the performance differences. Table 3 gives the $95 \%$ confidence interval. If this interval includes zero, performance differences are not considered to be statistically significant. From the table, we can observe significant performance differences for most pairs for at least one performance measure. Detailed performance results to further explore these differences will be presented next.

[Take in Table 3] 


\subsection{Performance Assessment Workload Control Order Release}

Figure 2 gives the lead time, the percentage tardy, and the mean tardiness results for the different pool sequencing rules and for Continuous (Figure 2a) and AM based (Figure 2b) release. Only results for PRD dispatching at the AM station and the scenario where jobs do not need to wait for a batch to be filled are given. The impact of these two dispatching related factors will be explored in the next section, our robustness analysis. The results are presented in the form of performance curves, where the left-hand starting point of the curves represents the tightest workload norm of 12 time units. The workload norm is loosened stepwise by moving from left to right in each graph, with each data point representing one workload norm (from 12 to 26 time units, in 2 time unit steps). In addition, the utmost right data point presents the results for an infinite workload norm, i.e. no order release control. Tightening the norms decreases the workload and, as a result, also reduces the throughput time on the shop floor.

\section{[Take in Figure 2]}

Results in Figure 2 show significant performance improvements across all performance measures considered when order release control is applied. This emphasizes the important role Workload Control order release can play in the context of AM shops. More specifically the following can be observed:

- Continuous vs AM based Release: By comparing Figure 2a with Figure $2 \mathrm{~b}$ we observe that AM based release is able to match the performance gains obtained for continuous release if the correct pool sequencing rule is chosen. Since AM based release takes the release decision less often than continuous release it can be considered to be the better alternative. The fact that, unlike continuous release, AM based release does not seek to constantly fill the norm also explains the general performance improvement in terms of the shop floor throughput times.

- Pool Sequencing: Performance differences across pool sequencing rules are minor if continuous release is applied (Figure 2a). PRD performs the worst of the nine sequencing rules. This is also reflected in the poor performance of MODCSCOR, MODLA, MODSA and MODSH, which all have a PRD component. This performance difference between PRD and non-PRD oriented sequencing rules is however magnified if AM based release is used (Figure 2b). If AM based release is applied then rules with a PRD component perform far worse than other rules. 
Workload Control order release traditionally realizes load balancing through its workload limit, which is enforced at the selection decision (Land, 2006). Our results highlight that this load balancing capability is diminished if AM based release is used (Figure 2b) in combination with a time-oriented pool sequencing rule (e.g. PRD) since workload limits have to account for the time it takes a job to pass the AM station. This operation throughput time of the AM station is highly variable. As a result, order release does not realize load balancing at the postprocessing shop. In contrast, CSCOR inherently creates a mix of jobs on the shop floor that realizes workload balancing. Meanwhile, the good performance of SH and SA for AM based release can be explained by these rules delaying the release of large jobs. This can be seen from Table 4, which gives the results for the pool waiting time, shop floor throughput time, and percentage tardy for each routing length. Only results for AM based release and a norm level of 12 time units are given in Table 4 . We chose the tightest norm level since here performance differences are the strongest.

\section{[Take in Table 4]}

Note that it is the timing element of PRD pool sequencing which causes the performance effect. This has been confirmed by additional simulation experiments with first-come-firstserved (FCFS) pool sequencing, which yielded similar results to PRD pool sequencing. The timing element ensures that all jobs become urgent and are considered first for release at a certain moment in time, whereas for rules without a timing element 'troublesome' jobs, such as jobs with large processing times, may be positioned at the end of the sequence until only these jobs remain (i.e. only being released during a low load period). It is this delay to jobs with large processing times that also explains the superior performance of continuous release for PRD pool sequencing; constantly seeking to fill the norms hinders the release of these jobs specifically during high load periods (Land et al., 2010). In general, the effect created by constantly filling up the norms diminishes the performance differences across the different pool sequencing rules. Note that this effect does not occur for AM based release (although this is also triggered continuously) since there is a longer time delay between each release decision for AM based release compared to continuous release.

Finally, Table 4 highlights that there is no difference in terms of shop floor throughput times for LA, SA, and SH. This was somewhat expected given that none of these three rules consider information from the post-processing shop. However, LA realizes longer pool waiting times since the operation throughput time at the AM station is longer. 


\subsection{Robustness Analysis: AM Dispatching}

Figure 3 and Figure 4 give the same results as Figure 2 but for LA and SH dispatching, respectively.

[Take in Figure 3 \& Figure 4]

There is a general increase in throughput times for LA dispatching and a general decrease in throughput times for $\mathrm{SH}$ dispatching. The decrease for $\mathrm{SH}$ dispatching compared to PRD dispatching can be explained by shorter operation throughput times at the AM station. This can be seen from Table 5, which gives the operation throughput time at the AM station and the shop floor throughput time for the post-processing shop for PRD, LA, and SH dispatching for continuous release and PRD pool sequencing. Meanwhile, the increase in shop floor throughput times for LA dispatching compared to PRD dispatching occurs at both the AM station and the post-processing shop. The increase in shop floor throughput times can be explained by the increase in the standard deviation of operation throughput times at the AM station. The AM station is the single gateway station to the post-processing shop, so any variability created at the AM station is directly transmitted to the downstream post-processing shop.

\section{[Take in Table 5]}

The results for the two focal dispatching rules (LA dispatching in Figure 3 and SH dispatching in Figure 4) confirm our findings on the performance of the two release methods and the pool sequencing rule. First, AM based release performs similar to continuous release if the correct pool sequencing rule is chosen. Second, pool sequencing rules that contain a PRD component are outperformed by other pool sequencing rules specifically if AM based release is applied. Thus, our findings are robust to the choice of dispatching rule at the AM station. The findings are also robust to our last experimental factor, whether a batch needs to be filled or not, as can be seen from Figure 5. Only results for continuous release are presented here since the performance impact of only processing a batch if it can be filled is negative. In general, waiting until the batch is filled does not improve performance. Note that we also do not present results for PRD dispatching since here no performance gains were expected. All results from the full factorial design that are not presented here are given in an online supplement to this study.

\section{[Take in Figure 5]}

\subsubsection{Analysis of AM Station Performance}


To better understand the impact of dispatching, and consequently the batching decision, at the AM station the results for the realized batch processing time, the batch size, the percentage of the production area filled, and the percentage of time the AM station is busy are presented in Table 6. The utilization of the AM station is the combined effect of the latter two measures, i.e. production area filled and busy time. Meanwhile, only the results for immediate release are presented since the workload norm did not significantly impact these results. As somewhat expected, if there is no need to wait then the AM station is busy most of the time, but the production area is not completely filled. In contrast, waiting until the batch is full increases the fill rate of the production area but the AM station is less busy. Meanwhile, performance differences across dispatching rules are very small if there is no need to wait. But when jobs have to wait until the production area is full, the desired effect of a better usage of the production area does indeed occur with LA dispatching - the utilized production area almost reaches $100 \%$. However, this is at the expense of starvation at the post-processing shop and, as a consequence, overall shop performance deteriorates. Meanwhile, for SH dispatching, batch processing times counter-intuitively increase if jobs have to wait until the batch is full. If a full batch is aimed for then any job arriving has to be loaded into the batch regardless of its processing time, and this can increase batch processing times.

[Take in Table 6]

\subsection{Discussion of Results}

Order book smoothing, which uses a time buffer to evenly distribute demand to the AM station, provides a distinct way of managing demand variability in AM shops (Hedenstierna et al., 2019). However, the existing literature on AM shop scheduling (e.g. Chergui et al., 2018) and order book smoothing (e.g. Hedenstierna et al., 2019) tends to overlook the post-processing operations downstream of the AM station. Hedenstierna et al. (2019) even completely neglect that the AM station is a parallel batch process where the realized capacity used for their calculations depends on several distinct factors (e.g. the fill rate of the production area), as highlighted in our study. In this sense, the AM shop is similar to a serial-batching scheduling problem (Pei et al., 2019a, Pei et al. 2019b; Kong et al., 2020) but in a to-order context. The serial-batching scheduling problem is typically approached by optimizing one station under the constraints imposed upon it by other stations. This is similar to Workload Control, which enforces a constraint - the workload limit - at downstream stations. However, Workload Control uses a sequential procedure. The constraints at downstream stations are enforced through order release control before the actual batching decision is realized. The constraints 
are reflected in the limited set of jobs from which the AM dispatching decision can select. Our study further highlighted that considering AM batching options at release as part of the pool sequencing rule does not significantly improve performance. Hence, considering workload balancing at the post-processing shop appears to be a better option, whilst batching decisions remain entirely under the control of the AM dispatching decision.

Finally, our study also provides an explanation for the inconsistency in expected performance of Workload Control in shops where there is a common first station in the routing of all jobs. First, Fernandes et al. (2015) showed that exercising order release control only at downstream stations leads to similar performance when compared to exercising release control at the single station that is the first in the routing of all jobs as well as at the downstream stations. Second, Cransberg et al. (2016) argued that if the complexity to be controlled resides at an upstream station then it should be controlled at order release while if the complexity to be controlled resides at a downstream station then it should be controlled by dispatching. Our findings show that for AM based release the load balancing capability of enforcing the workload limit as part of the selection decision is severely weakened. But Workload Control can still ensure that the set of jobs available for dispatching on the shop floor allows for load balancing. This can be achieved through the pool sequencing rule. So, our findings confirm Cransberg et al. (2016) in the sense that the workload limit has a stronger impact at upstream stations, given the increase in delay between the release decision and the actual materialization of the workload at downstream stations, while the sequence in which jobs are released has a stronger effect at downstream stations. It is also this change in sequence rather than the load limiting that explains the results in Fernandes et al. (2015) for a purely make-to-order context, where similar to our results - only continuous release is able to significantly improve tardiness performance.

\section{Conclusions}

AM shops typically operate as engineer-to-order shops producing high-variety, low volume products. A main factor determining performance in an AM shop is post processing, given that parts manufactured by AM can typically not be used directly. Post-processing poses significant challenges for production control since routings and processing requirements vary. Although the planning and control needs of post-processing appear to be a good fit with the Workload Control concept, the structure presented by AM shops has received insufficient attention in the Workload Control literature. A parallel batch process, where the actual AM operation takes place, precedes the post-processing shop that is to be controlled. This specific structure raises 
several questions related to the design of Workload Control in the context of AM: In the context of AM, where an AM station precedes a general flow shop, when should the order release decision be taken? And, what kind of pool sequencing rule should be applied to consider jobs for release to the AM shop?

Using simulation, we have shown that triggering the release decision only when a batch is complete at the AM station realizes similar performance outcomes to triggering release whenever an operation is complete at the post-processing shop, but only if a suitable pool sequencing rule is applied. CSCOR was identified as the best-performing pool sequencing rule since it strikes the best performance balance across jobs with long and short routings. CSCOR inherently creates a mix of jobs for the post-processing shop that balances the workload. This is important since load balancing via the workload norm, as is typical for Workload Control, becomes ineffective since the norm has to allow for the operation throughput time at the AM station and its variability. By using a time-based pool sequencing rule, the effect of Workload Control is restricted to workload limiting, i.e. work from the shop floor is shifted into the pool without any reduction in lead times.

\subsection{Managerial Implications}

AM shops are complex to manage. This study has highlighted the potential of Workload Control order release to improve performance in AM environments. But it also highlighted important contingency factors and interactions. For example, if AM based release is applied, then enforcing the workload norm as part of the selection decision does not realize workload balancing. This calls for the use of pool sequencing rules that focus on load balancing. The major factor triggering this interaction is the fact that we considered no decoupling stock between the AM station and the post-processing shop. This means the decision concerning which job should be released to the AM station and which job should be released to the postprocessing shop were not taken independently. We consider this justified since a job that cannot be processed at post-processing should also not be released to the AM station. Otherwise inventory may accumulate. A consequence of not using decoupling inventory between the AM station and the post-processing shop is that any variability introduced at the AM station will propagate to the post-processing shop. So, managers must realize that the scheduling decision at $\mathrm{AM}$ cannot be taken independently from post-processing considerations. However, while decoupling stock simplifies the control problem, it necessarily leads to longer lead times, which runs counter to the main aim of $\mathrm{AM}$ - the fast provision of highly customized products to order. Finally, in terms of dispatching at the AM station, our results suggest that $\mathrm{SH}$ dispatching 
should be adopted. However, SH dispatching may become dysfunctional if a full batch is targeted.

\subsection{Limitations and Future Research}

A main limitation is that we do not consider different material types or material usage. While this is justified by the need to keep the number of experiments to a reasonable level, future research could explore the impact of different material types and material usage. For example, considering different material types leads to set-ups and set-up costs even in the context of AM where set-up is often minimized. This consequently introduces another objective into the batching considerations. Another limitation is our focus on rule-based Workload Control and consequently a rule based batching decision at the AM station. Future research could explore the impact of optimization-based Workload Control, potentially with a hierarchical planning structure. This allows for integrating the batching and release decisions, which are executed separately by the rule-based greedy heuristic used in our study. A first outline on how lot-sizing considerations can be accommodated in optimization-based Workload Control was already presented in Missbauer (2002). Considering batching as part of release, thereby releasing batches rather than jobs, also allows for addressing our final major limitation that we did not control the AM station. While this is justified by the use of rule-based Workload Control, which relies on controlling workload aggregates, optimization-based Workload Control and batchwise release allows for creating batch load aggregates (given by the maximum job workload in the batch) that can be controlled. Finally, our study has focused on AM; however, the shop structure we have modelled could also be found in many other contexts, including the steel industry, semi-conductor plants, and emergency departments, where an initial assessment and/or treatment process (including triage) precedes post assessment, treatment, and admission/discharge activities. It could therefore be interesting to explore how the findings can be translated to these contexts.

\section{References}

Achillas, C., Aidonis, D., Iakovou, E., Thymianidis, M., and Tzetzis, D., 2015, A methodological framework for the inclusion of modern additive manufacturing into the production portfolio of a focused factory, Journal of Manufacturing Systems, 37, 1, 328339.

Alexander, P., Allen, S., and Dutta, D., 1998, Part orientation and build cost determination in layered manufacturing, Computer-Aided Design, 30, 5, 343-356. 
ASTM, 2012, International Standard F2792. 2012. Standard Terminology for Additive Manufacturing Technologies, ASTM, West Conshohocken, PA.

Baker, K.R., and Kanet, J.J., 1983, Job shop scheduling with modified operation due-dates, Journal of Operations Management, 4, 1, 11-22.

Bechte, W., 1994, Load-oriented manufacturing control just-in-time production for job shops, Production Planning \& Control, 5, 3, 292 - 307.

Bergamaschi, D., Cigolini, R., Perona, M., and Portioli, A., 1997, Order review and release strategies in a job shop environment: A review and a classification, International Journal of Production Research, 35, 2, 399-420.

Berman, B., 2012, 3-D printing: The new industrial revolution, Business Horizons, 55, 155162.

Brennan, L., Ferdows, K., Godsell, J., Golini, R., Keegan, R., Kinkel, S., Srai, J. S., and Taylor, M., 2015, Manufacturing in the world: where next? International Journal of Operations \& Production Management, 35, 9, 1253-1274.

Chergui, A., Hadj-Hamou, K., and Vignat, F., 2018, Production scheduling and nesting in additive manufacturing, Computers \& Industrial Engineering, 126, 292-301.

Cigolini, R., and Portioli-Staudacher, A., 2002, An experimental investigation on workload limiting methods with ORR policies in a job shop environment, Production Planning \& Control, 13, 7, 602-613.

Cransberg, V., Land, M.J., Hicks, C., and Stevenson, M., 2016, Handling the complexities of real-life job shops when implementing workload control: a decision framework and case study, International Journal of Production Research, 54, 4, 1094-1109.

Delic, M., Eyers, D. R., and Mikulic, J., 2019, Additive manufacturing: empirical evidence for supply chain integration and performance from the automotive industry, Supply Chain Management: An International Journal, 24, 5, 604-621.

Enns, S.T., 1995, An integrated system for controlling shop loading and work flows, International Journal of Production Research, 33, 10, 2801-2820.

Eyers, D.R., Potter, A.T., Gosling, J. and Naim, M.M., 2018, The flexibility of industrial additive manufacturing systems, International Journal of Operations \& Production Management, 38, 12, 2313-2343.

Eyers, D.R. and Potter, A.T., 2015, E-commerce channels for additive manufacturing: an exploratory study, Journal of Manufacturing Technology Management, 26, 3, 390-411. 
Fernandes, N.O., Land, M.J., and Carmo-Silva, S., 2016; Aligning workload control theory and practice: lot splitting and operation overlapping issues, International Journal of Production Research, 54, 10, 2965-2975.

Fernandes, N.O., Silva, C., and Carmo-Silva, S., 2015, Order release in the hybrid MTO-FTO production, International Journal of Production Economics, 170, Part B, 513-520.

Fernandes, N.O., and Carmo-Silva, S., 2011, Workload Control under continuous order release, International Journal of Production Economics, 131, 257 - 262.

Fredendall, L.D., Ojha, D., and Patterson, J.W., 2010, Concerning the theory of workload control, European Journal of Operational Research, 201, 1, 99-111.

Gonzalez-R, P.L., Calle, M., and Andrade-Pineda, J.L., 2018, Job shop management of products under internal lifespan and external due date, International Journal of Production Research, 56, 16, 5457-5474.

Haeussler, S., and Netzer, P., 2019, Comparison between rule- and optimization-based workload control concepts: a simulation optimization approach, International Journal of Production Research, in press.

Hedenstierna, C.P.T., Disney, S.M., Eyers, D.R., Holmström, J., Syntetos, A.A., and Wang, X., 2019, Economies of collaboration in built-to-model operations, Journal of Operations Management, 1-21.

Hendry, L.C., Huang, Y., and Stevenson, M., 2013, Workload control: Successful implementation taking a contingency-based view of production planning \& control, International Journal of Operations \& Production Management, 33, 1, 69-103.

Holmström, J., Partanen, J., Tuomi, J. and Walter, M., 2010, Rapid manufacturing in the spare parts supply chain: alternative approaches to capacity deployment, Journal of Manufacturing Technology Management, 21, 6, 687-697.

Holmström, J., Holweg, M., Khajavi, S. H., and Partanen, J., 2016, The direct digital manufacturing (r) evolution: definition of a research agenda, Operations Management Research, 9, 1-2,1-10.

Hutter, T., Haeussler, S., \& Missbauer, H., 2018, Successful implementation of an order release mechanism based on workload control: a case study of a make-to-stock manufacturer, International Journal of Production Research, 56, 4, 1565-1580.

Kacar, N. B., Irdem, D. F., and Uzsoy, R., 2011, An experimental comparison of production planning using clearing functions and iterative linear programming-simulation algorithms, IEEE Transactions on Semiconductor Manufacturing, 25, 1, 104-117. 
Kanet, J.J., 1988, Load-limited order release in job shop scheduling systems, Journal of Operations Management, 7, 3, 44-58.

Khorram Niaki, M., and Nonino, F., 2016, Additive manufacturing management: a review and future research agenda, International Journal of Production Research, 55, 5, 1419-1439.

Kong, M., Pei, J., Xu, J., Liu, X., Yu, X., and Pardalos, P.M., 2020, A robust optimization approach for integrated steel production and batch delivery scheduling with uncertain rolling times and deterioration effect, International Journal of Production Research, in print

Land, M.J., 2006, Parameters and sensitivity in workload control, International Journal of Production Economics, 104, 2, 625-638.

Land, M.J., and Gaalman, G.J.C., 1998, The performance of workload control concepts in job shops: Improving the release method, International Journal of Production Economics, 5657, 347-364.

Land, M.J., and Gaalman, G.J.C, 1996, Workload control concepts in job shops: A critical assessment, International Journal of Production Economics, 46-47, 535-538.

Land, M.J., Stevenson, M., Thürer, M., and Gaalman, G.J.C., 2015; Job Shop Control: In Search of the Key to Delivery Improvements, International Journal of Production Economics, 168, 257-266.

Land, M.J., Su, N.P.B. and Gaalman, G..J.C, 2010, In search of the key to delivery improvement, 16th International Working Seminar on Production Economics, 1st - 5th March, Innsbruck, Austria, Conference Proceedings, 2, 297-308.

Li, Q., Kucukkoc, I., and Zhang, D.Z., 2017, Production planning in additive manufacturing and 3D printing, Computers \& Operations Research, 83, 157-172.

Liu, P., Huang, S.H., Mokasdar, A., Zhou, H., and Hou, L., 2014, The impact of additive manufacturing in the aircraft spare parts supply chain: supply chain operation reference (scor) model based analysis, Production Planning \& Control, 25, 1169-1181.

McCarthy, B. L., Blome, C., Olhager, J., Srai, J. S., and Zhao, X., 2016, Supply chain evolution-theory, concepts and science, International Journal of Operations \& Production Management, 36, 12, 1696-1718.

Mellor, S., Hao, L., and Zhang, D., 2014, Additive manufacturing: A framework for implementation, International Journal of Production Economics, 149, 194-201.

Missbauer, H., 2002, Lot sizing in workload control systems, Production Planning \& Control, $13,7,649-664$.

Oosterman, B., Land, M.J., and Gaalman, G., 2000, The influence of shop characteristics on workload control, International Journal of Production Economics, 68, 1, 107-119. 
Pei, J., Liu, X., Fan, W., Pardalos, P. M., and Lu, S., 2019a, A hybrid BA-VNS algorithm for coordinated serial-batching scheduling with deteriorating jobs, financial budget, and resource constraint in multiple manufacturers, Omega, 82, 55-69.

Pei, J., Wei, J., Liao, B., Liu, X., and Pardalos, P. M., 2019b, Two-agent scheduling on bounded parallel-batching machines with an aging effect of job-position-dependent, Annals of Operations Research, 1-33.

Perona, M., and Portioli, A., 1998, The impact of parameter setting in load oriented manufacturing control, International Journal of Production Economics, 55, 133 - 142.

Petrovic, V., Vicente Haro Gonzalez, J., Jordá Ferrando, O., Delgado Gordillo, J., Ramón Blasco Puchades, J., and Portolés Griñan, L., 2011, Additive layered manufacturing: sectors of industrial application shown through case studies, International Journal of Production Research, 49, 4, 1061-1079.

Philipoom, P.R., Malhotra, M.K., and Jensen, J.B., 1993, An evaluation of capacity sensitive order review and release procedures in job shops, Decision Sciences, 24, 6, 1109-1133.

Piili, H., Happonen, A., Vaisto, T., Venkataramanan, V., Partanen, J., and Salminen, A, 2015, Cost estimation of laser additive manufacturing of stainless steel. Physics Procedia, 78, 388-396.

Portioli-Staudacher, A., and Tantardini, M., 2012, A lean-based ORR system for non-repetitive manufacturing, International Journal of Production Research, 50, 12, 3257-3273.

Pour, M. A., Zanardini, M., Bacchetti, A., and Zanoni, S., 2016, Additive manufacturing impacts on productions and logistics systems. IFAC-PapersOnLine, 49, 12, 1679-1684.

Rickenbacher, L., Spierings, A., and Wegener, K., 2013, An integrated cost model for selective laser melting (SLM), Rapid Prototyping Journal, 19, 3, 208-214.

Ryan, M.J., Eyers, D.R., Potter, A.T., Purvis, L., and Gosling, J., 2017, 3D printing the future: scenarios for supply chains reviewed, International Journal of Physical Distribution \& Logistics Management, 47, 10, 992-1014.

Sabuncuoglu, I., and Karapinar, H.Y., 2000, A load-based and due-date-oriented approach to order review/release in job shops, Decision Sciences, 31, 2, 413-447.

Scheffé, H., 1959, The Analysis of Variance, New York: Wiley

Silva, C., Stevenson, M., and Thürer, M., 2015, A Case Study of the Successful Implementation of Workload Control: A Practitioner-led Approach, Journal of Manufacturing Technology Management, 26, 2, 280-296. 
Stevenson, M., Hendry, L.C., and Kingsman, B.G., 2005, A review of production planning and control: The applicability of key concepts to the make to order industry, International Journal of Production Research, 43, 5, 869-898.

Thomas-Seale, L.E.J., Kirkman-Brown, J.C., Attallah, M.M., Espino, D.M., and Shepherd, D.E.T., 2018, The barriers to the progression of additive manufacture: perspectives from UK industry, International Journal of Production Economics, 198, 104-118.

Thürer, M., Stevenson, M., Aitken, J., and Silva, C., 2020, State-Dependent Service Rates in Make-to-Order Shops: An Assessment by Simulation, Operations Management Research, (in print)

Thürer, M., Land, M.J., Stevenson, M., Fredendall, L.D., and Godinho Filho, M., 2015, Concerning Workload Control and Order Release: The Pre-Shop Pool Sequencing Decision, Production \& Operations Management, 24, 7, 1179-1192.

Thürer, M., Stevenson, M., Silva, C., Land, M.J., Fredendall, L.D., and Melnyk, S.A., 2014, Lean control for make-to-order companies: Integrating customer enquiry management and order release, Production \& Operations Management, 23, 3, 463-476.

Thürer, M., Stevenson, M., Silva, C., Land, M.J., and Fredendall, L.D., 2012, Workload control (WLC) and order release: A lean solution for make-to-order companies, Production \& Operations Management, 21, 5, 939-953.

Tuck, C.J., Hague, R.J., Ruffo, M., Ransley, M., and Adams, P., 2008, Rapid manufacturing facilitated customization, International Journal of Computer Integrated Manufacturing, 21, 245-258.

Wiendahl, H.P., Gläßner, J., and Petermann, D., 1992, Application of load-oriented manufacturing control in industry, Production Planning \& Control, 3, 2, 118 - 129.

Wisner, J. D., 1995, A review of the order release policy research, International Journal of Operations \& Production Management, 15, 6, 25-40.

Zäpfel, G. and Missbauer, H., 1993, New concepts for production planning and control, European Journal of Operational Research, 67, 297-320.

Zhang, Y. and Bernard, A. 2013, Generic build time estimation model for parts produced by SLS High Value Manufacturing: Advanced Research in Virtual and Rapid Prototyping, CRC Press, 43-48. 
Table 1: Summary of Shop and Job Characteristics

\begin{tabular}{|c|c|c|}
\hline 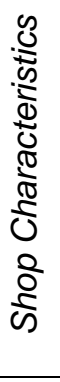 & $\begin{array}{r}\text { Routing Variability } \\
\text { No. of Additive Manufacturing (AM) Station } \\
\text { No. of Post Processing Stations } \\
\text { Station Capacities } \\
\text { Post Processing Station Utilization Rate } \\
\text { AM Station Utilization Rate } \\
\text { AM Station Production Area (Build Envelope) } \\
\text { AM Station Production Rate }\end{array}$ & $\begin{array}{l}\text { Random routing; directed, no re-entrant } \\
\text { flows } \\
1 \\
6 \\
\text { All equal } \\
90 \% \\
\text { Dependent on Dispatching Rule } \\
10 \text { space units } \\
1 \text { time unit per space unit } \\
\end{array}$ \\
\hline 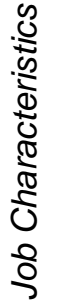 & $\begin{array}{r}\text { No. of Operations per Job } \\
\text { Post Processing Operation Processing Times } \\
\text { AM Operation Processing Times } \\
\text { Height (Space Units) } \\
\text { Area (Space Units) } \\
\text { Due Date Determination Procedure } \\
\text { Inter-Arrival Times }\end{array}$ & $\begin{array}{l}\text { Discrete Uniform [2, 7] } \\
\text { Truncated 2-Erlang; }(\text { mean }=1 ; \max =4) \\
\text { Dependent on Height } \\
\text { Truncated 2-Erlang; }(\text { mean }=2) \\
\text { Truncated 2-Erlang; }(\text { mean }=2 ; \max =10) \\
\text { Due Date = Entry Time }+d ; d U \sim[36,51] \\
\text { Exp. Distribution; mean }=0.648\end{array}$ \\
\hline
\end{tabular}

Table 2: Summary of Experimental Factors

\begin{tabular}{|l|l|}
\hline Experimental Factor & Level \\
\hline Workload Norm (9 level) & $12,14,16,18,20,22,24,26$ time units and infinite \\
\hline Release Timing (2 level) & Continuous and Additive Manufacturing (AM) based \\
\hline Pool Sequencing Rule (9 level) & $\begin{array}{l}\text { Planned Release Date (PRD), Capacity Slack Corrected } \\
\text { (CSCOR), Smallest Area (SA), Largest Area (LA), Shortest } \\
\text { Height (SH), Modified CSCOR (MODCSCOR), Modified } \\
\text { Smallest Area (MODSA), Modified Largest Area (MODLA) and } \\
\text { Modified Smallest Height (MODSH) }\end{array}$ \\
\hline $\begin{array}{l}\text { Dispatching Additive Machine (3 } \\
\text { level) }\end{array}$ & $\begin{array}{l}\text { Planned Release Date (PRD), Largest Area (LA) and Shortest } \\
\text { Height (SH) }\end{array}$ \\
\hline $\begin{array}{l}\text { Production Area Needs to be Full } \\
\text { (2 level) }\end{array}$ & No and Yes \\
\hline
\end{tabular}


Table 3: Results for Scheffé Multiple Comparison Procedure

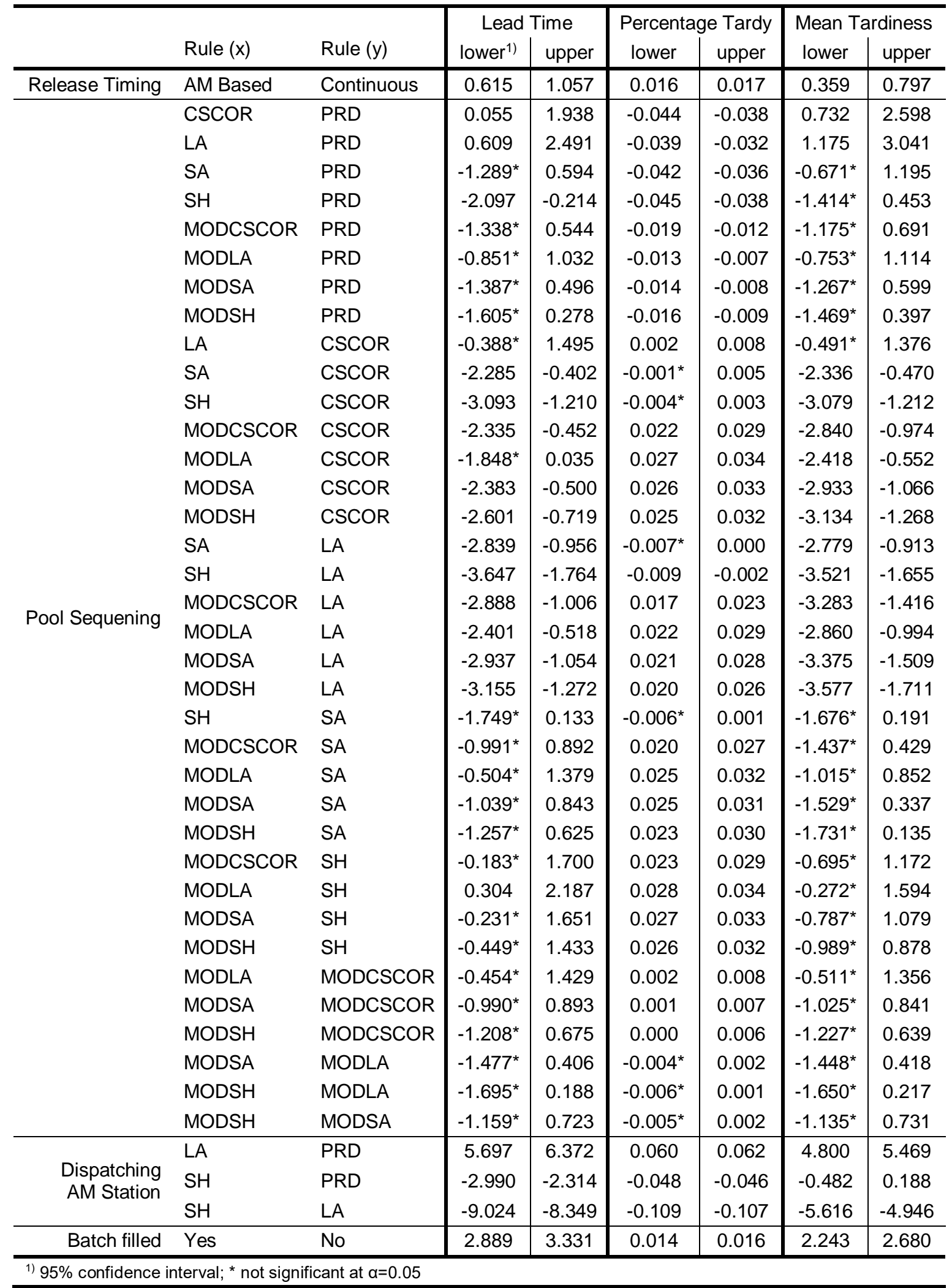


Table 4: Performance Results Across Routing Length AM based Release, Norm of 12 time units and PRD dispatching

\begin{tabular}{|c|c|c|c|c|c|c|c|}
\hline & $\begin{array}{r}\text { Pool Sequencing } \\
\text { Rule }\end{array}$ & $\begin{array}{l}\text { Routein } \\
\mathrm{g} \\
\text { Length } \\
1\end{array}$ & $\begin{array}{l}\text { Routein } \\
9 \\
\text { Length } \\
2\end{array}$ & $\begin{array}{l}\text { Routein } \\
9 \\
\text { Length } \\
3\end{array}$ & $\begin{array}{l}\text { Routein } \\
\text { g } \\
\text { Length } \\
4\end{array}$ & $\begin{array}{l}\text { Routein } \\
9 \\
\text { Length } \\
5\end{array}$ & $\begin{array}{l}\text { Routein } \\
g \\
\text { Length } \\
6\end{array}$ \\
\hline \multirow{5}{*}{$\begin{array}{r}\text { Pool } \\
\text { waiting } \\
\text { time }\end{array}$} & PRD & 6.32 & 7.89 & 8.07 & 7.43 & 6.22 & 4.87 \\
\hline & CSCOR & 6.45 & 6.88 & 6.11 & 4.95 & 3.91 & 3.08 \\
\hline & LA & 3.71 & 5.01 & 6.34 & 7.80 & 9.63 & 11.63 \\
\hline & SA & 3.42 & 4.30 & 5.20 & 6.13 & 7.15 & 8.43 \\
\hline & $\mathrm{SH}$ & 3.36 & 4.22 & 4.99 & 5.91 & 6.81 & 7.96 \\
\hline \multirow{5}{*}{$\begin{array}{r}\text { Shop floor } \\
\text { throughput } \\
\text { time }\end{array}$} & PRD & 21.42 & 24.68 & 26.17 & 27.40 & 28.69 & 30.03 \\
\hline & CSCOR & 20.59 & 24.18 & 25.80 & 26.78 & 27.38 & 27.81 \\
\hline & LA & 21.46 & 24.96 & 26.04 & 26.35 & 26.34 & 26.30 \\
\hline & SA & 21.07 & 24.65 & 25.83 & 26.22 & 26.25 & 26.23 \\
\hline & $\mathrm{SH}$ & 20.90 & 24.57 & 25.80 & 26.15 & 26.21 & 26.20 \\
\hline \multirow{5}{*}{$\begin{array}{r}\text { Percentag } \\
\text { e tardy }\end{array}$} & PRD & $15.32 \%$ & $20.82 \%$ & $23.06 \%$ & $23.96 \%$ & $24.21 \%$ & $24.25 \%$ \\
\hline & CSCOR & $5.94 \%$ & $8.50 \%$ & $9.74 \%$ & $10.20 \%$ & $10.42 \%$ & $10.51 \%$ \\
\hline & LA & $4.63 \%$ & $7.81 \%$ & $10.05 \%$ & $11.92 \%$ & $13.65 \%$ & $15.13 \%$ \\
\hline & SA & $4.21 \%$ & $7.23 \%$ & $9.36 \%$ & $11.05 \%$ & $12.51 \%$ & $13.82 \%$ \\
\hline & $\mathrm{SH}$ & $4.03 \%$ & $6.97 \%$ & $8.95 \%$ & $10.63 \%$ & $12.07 \%$ & $13.32 \%$ \\
\hline
\end{tabular}

Table 5: Operation Throughput Times Additive Manufacturing and Shop Floor Throughput Times Post Processing Shop for PRD, LA and SH dispatching and Continuous Release with

PRD Pool Sequencing

\begin{tabular}{|c|c|c|c|c|c|c|c|c|c|}
\hline & \multicolumn{3}{|c|}{ PRD } & \multicolumn{3}{|c|}{ LA } & \multicolumn{3}{|c|}{$\mathrm{SH}$} \\
\hline & OTT $^{11}$ & SDOTT $^{2)}$ & $\mathrm{SFT}^{3)}$ & OTT & SDOTT & SFT & OTT & SDOTT & SFT \\
\hline Infinite & 8.01 & 2.77 & 24.77 & 9.07 & 3.80 & 26.16 & 5.50 & 2.81 & 24.47 \\
\hline Norm 26 & 7.86 & 2.73 & 24.45 & 8.50 & 3.45 & 25.32 & 5.50 & 2.82 & 24.12 \\
\hline Norm 24 & 7.81 & 2.72 & 24.28 & 8.38 & 3.38 & 25.06 & 5.49 & 2.81 & 23.99 \\
\hline Norm 22 & 7.77 & 2.71 & 24.09 & 8.24 & 3.31 & 24.69 & 5.47 & 2.79 & 23.80 \\
\hline Norm 20 & 7.70 & 2.69 & 23.78 & 8.06 & 3.22 & 24.30 & 5.46 & 2.79 & 23.50 \\
\hline Norm 18 & 7.56 & 2.65 & 23.37 & 7.85 & 3.11 & 23.68 & 5.46 & 2.82 & 23.11 \\
\hline Norm 16 & 7.42 & 2.61 & 22.72 & 7.61 & 2.98 & 22.87 & 5.44 & 2.82 & 22.48 \\
\hline Norm 14 & 7.25 & 2.56 & 21.73 & 7.33 & 2.84 & 21.72 & 5.42 & 2.82 & 21.57 \\
\hline Norm 12 & 7.04 & 2.49 & 20.33 & 7.03 & 2.68 & 20.16 & 5.37 & 2.79 & 20.22 \\
\hline
\end{tabular}


Table 6: Realized Batch Processing Times, Batch Size, Area Filled and Busy Time for Immediate Release: PRD, LA and SH Dispatching

\begin{tabular}{|c|c|c|c|c|c|}
\hline \multicolumn{2}{|c|}{ Dispatching at AM station: } & Time $^{1)}$ & Size $^{2)}$ & Area $^{3)}$ & Busy ${ }^{4}$ \\
\hline \multirow{2}{*}{ PRD } & No need to wait & 2.56 & 3.98 & $79.36 \%$ & $99.12 \%$ \\
\hline & Wait for batch filled & 2.74 & 4.63 & $92.31 \%$ & $91.43 \%$ \\
\hline \multirow{2}{*}{ LA } & No need to wait & 2.53 & 3.94 & $78.51 \%$ & $98.99 \%$ \\
\hline & Wait for batch filled & 2.78 & 4.94 & $98.46 \%$ & $86.95 \%$ \\
\hline \multirow{2}{*}{$\mathrm{SH}$} & No need to wait & 2.46 & 3.83 & $76.32 \%$ & $99.22 \%$ \\
\hline & Wait for batch filled & 2.56 & 4.18 & $83.36 \%$ & $94.58 \%$ \\
\hline
\end{tabular}




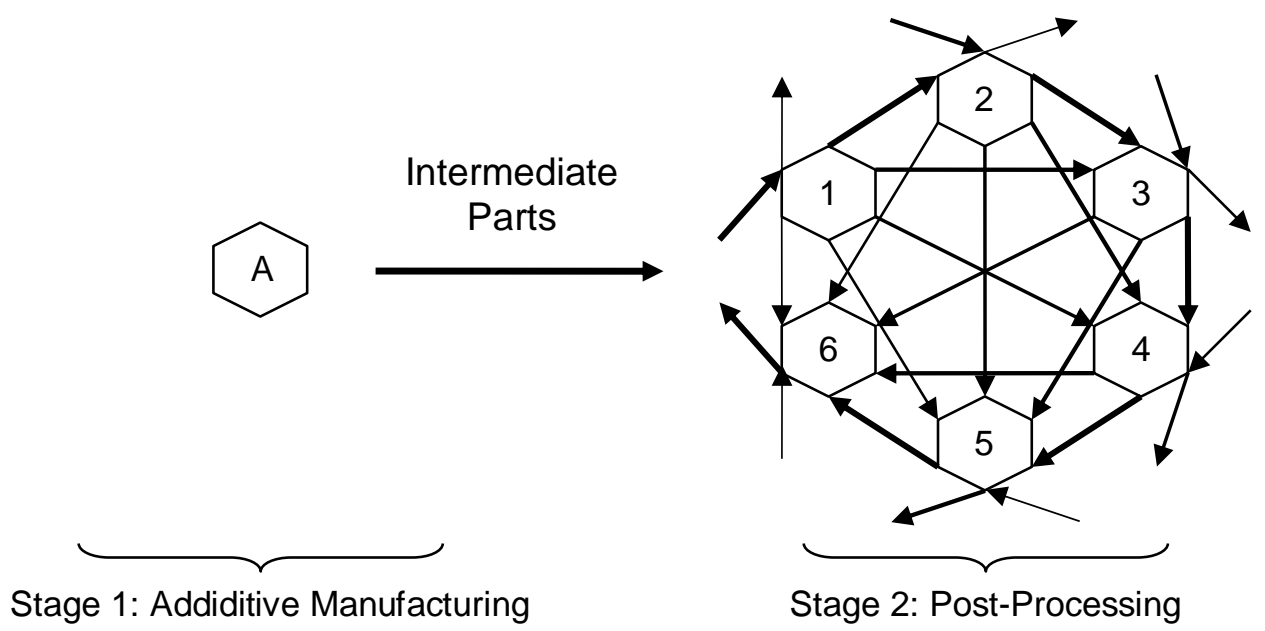

Figure 1: Schematization of Modelled Shop Structure 

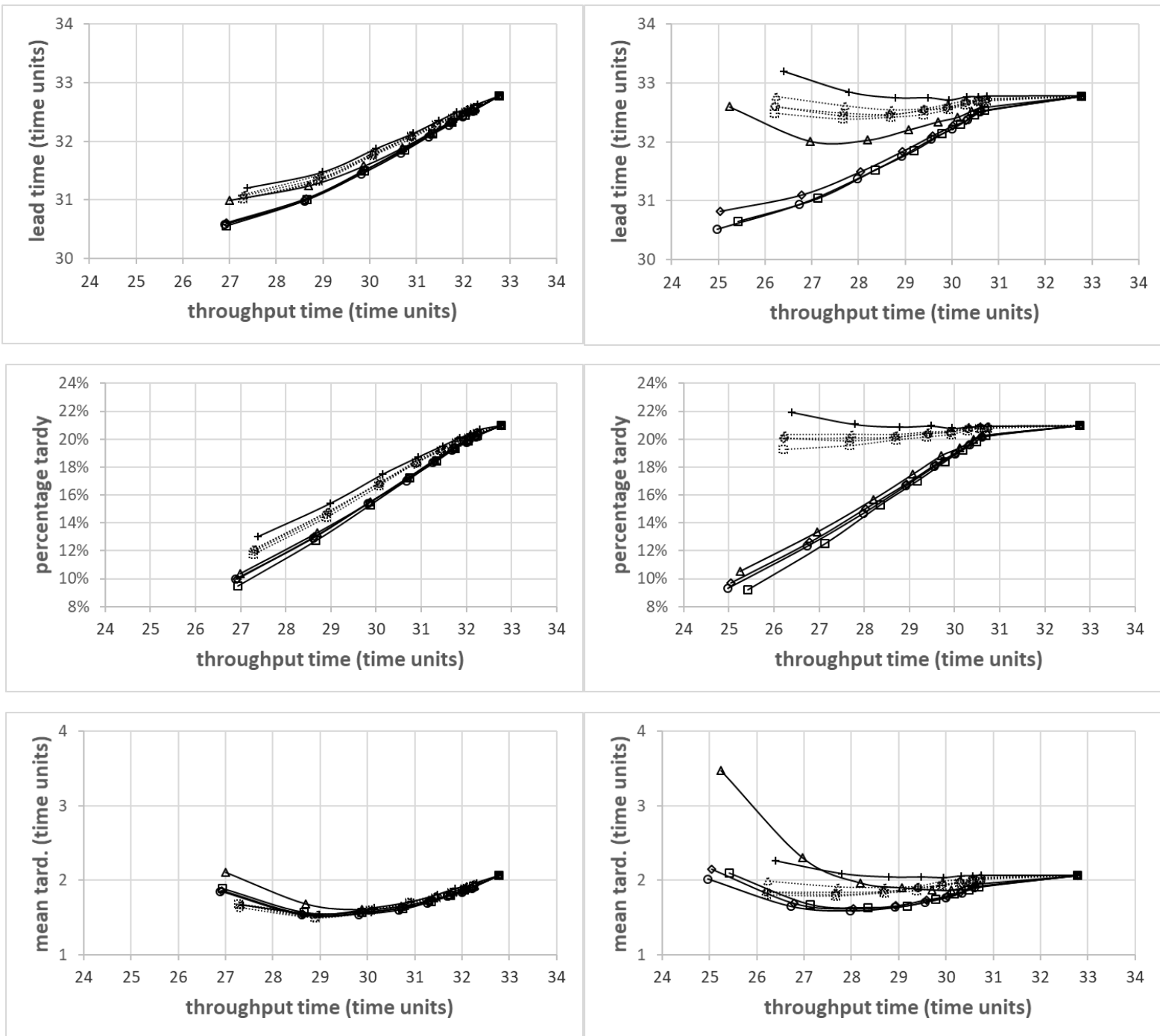

(a) Continuous

(b) AM Based

\begin{tabular}{|c|c|c|}
\hline$\mp$ PRD & $\rightarrow$ CSCOR & $\triangle L A$ \\
\hline$\rightarrow S A$ & $\rightarrow \mathrm{SH}$ & .........MODCSCOR \\
\hline$\cdots \cdots$ MODLA & .........MODSA & $\cdots \cdots \cdot$ MODSH \\
\hline
\end{tabular}

Figure 2: Results for Continuous and AM based release for PRD dispatching and no need to wait for a batch to be filled 

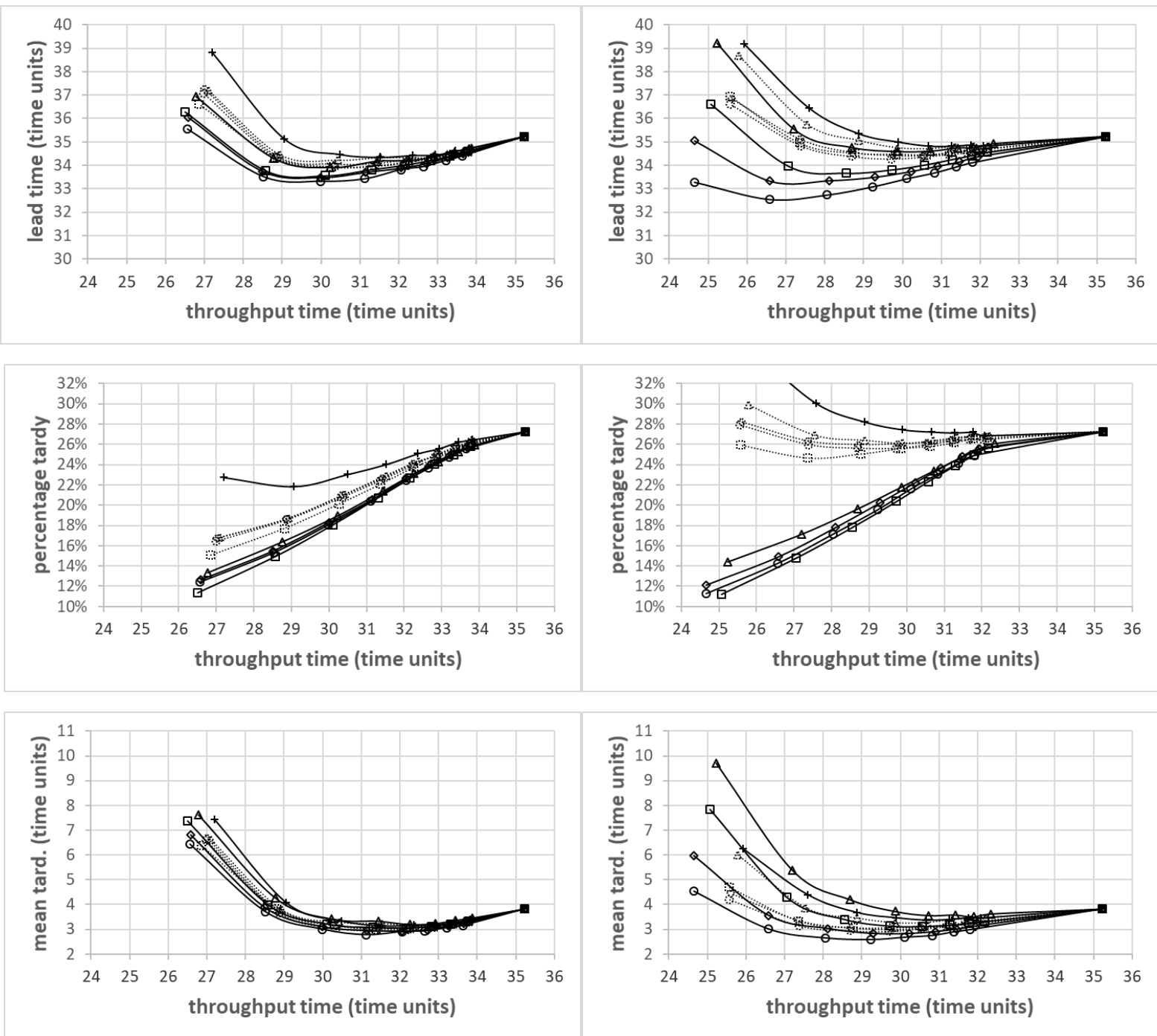

(a) Continuous

(b) AM Based

\begin{tabular}{|c|c|c|}
\hline$\longrightarrow$ PRD & $\square-\mathrm{CSCOR}$ & $\triangle \mathrm{LA}$ \\
\hline$\multimap S A$ & $\rightarrow \mathrm{SH}$ & $\cdots . . . \cdots M O D C S C O R$ \\
\hline ..... MODLA & $\ldots . . . . M O D S A$ & $\ldots * \cdots M O D S H$ \\
\hline
\end{tabular}

Figure 3: Results for Continuous and AM based release for LA dispatching and no need to wait for a batch to be filled 

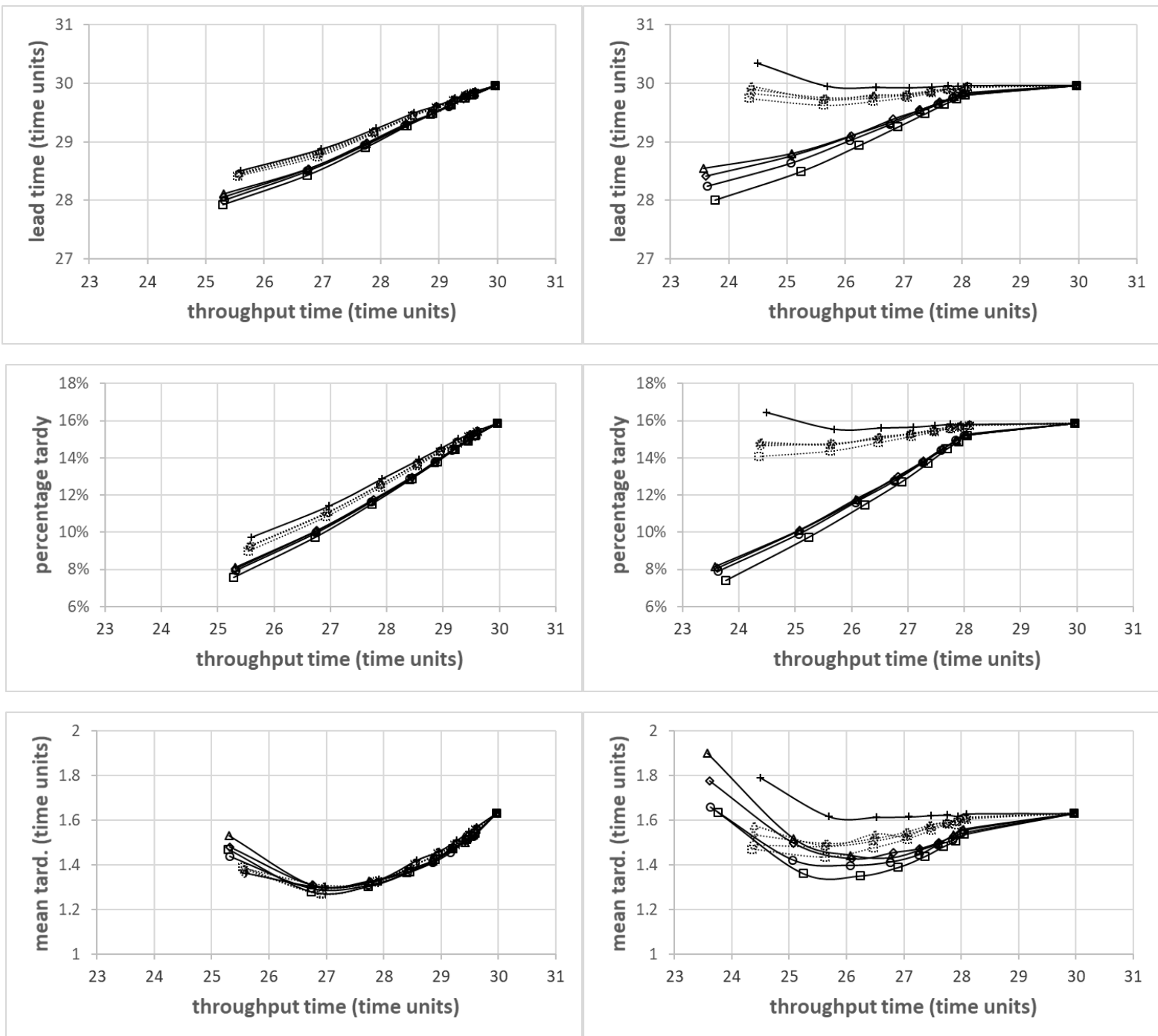

(a) Continuous

(b) AM Based

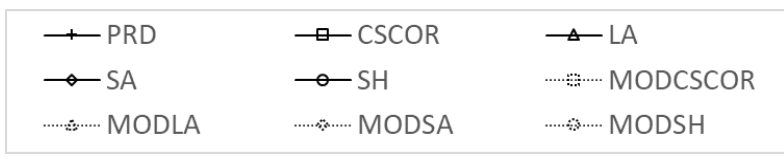

Figure 4: Results for Continuous and AM based release for SH dispatching and no need to wait for a batch to be filled 

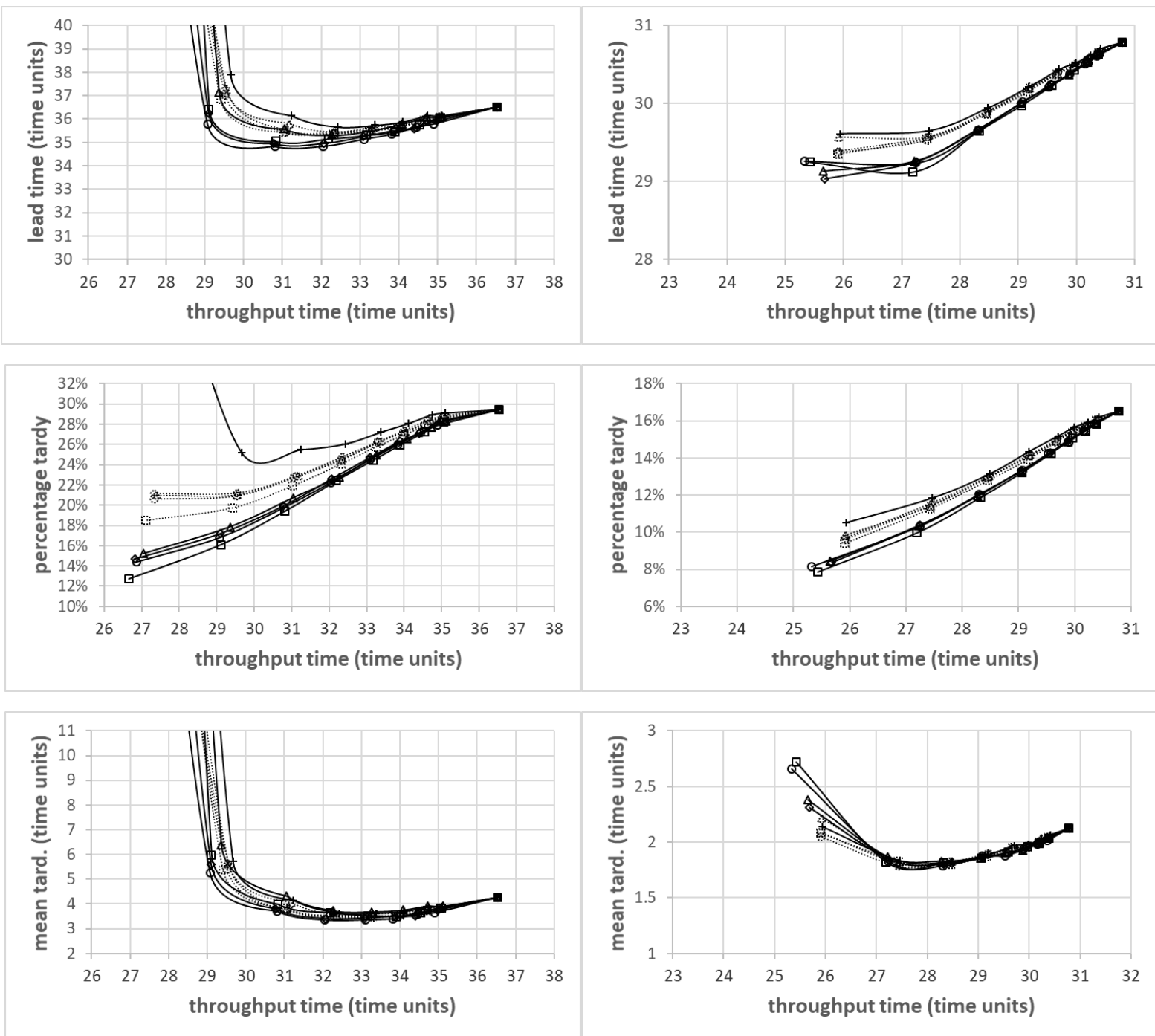

(a) LA Dispatching

(b) SH Dispatching

\begin{tabular}{|c|c|c|}
\hline$\multimap P R D$ & 匹-CSCOR & $\triangle \mathrm{LA}$ \\
\hline$\multimap S A$ & $\rightarrow-\mathrm{SH}$ & $\cdots \cdot \cdots$ MODCSCOR \\
\hline$\cdots$ MODLA & ........MODSA & $\ldots . . . . . M O D O M H$ \\
\hline
\end{tabular}

Figure 5: Results for LA dispatching and SH dispatching for Continuous Release when jobs need to wait until a batch can be filled 